"Mircea cel Batran" Naval Academy Scientific Bulletin, Volume XIX - 2016 - Issue 1

Published by "Mircea cel Batran" Naval Academy Press, Constanta, Romania // The journal is indexed in:

PROQUEST / DOAJ / DRJI / JOURNAL INDEX / I2OR / SCIENCE LIBRARY INDEX / Google Scholar / Crossref /

Academic Keys / ROAD Open Access / OAJI / Academic Resources / Scientific Indexing Services / SCIPIO

\title{
UNMANNED AERIAL VEHICLES IN THE NAVY: ITS BENEFITS
}

\author{
Gonçalo Castanheira ROSA ${ }^{1}$ \\ Mario Monteiro MARQUES ${ }^{1}$ \\ Victor LOBO $^{1}$ \\ ${ }^{1}$ CINAV, Portuguese Navy Research Center, Almada, Portugal
}

\begin{abstract}
Military investment in UAV research, systems, and applied technologies is increasing, and potential uses for UAVs in civil and military operations are in development. These developments, along with growing scientific interest in UAVs, are fueling commercial interest in the unmanned market. The growing enthusiasm for UAVs is not unfounded. The vehicles offer a unique range of features, most notably ultra-long endurance and high-risk mission acceptance, which cannot be reasonably performed by manned aircraft. Coupled with advances in automation and sensor technologies, and the potential for costs savings, it is understandable that interest in and demand for UAVs is on the rise.

Organizations like the Navy have all the benefits to accompany the technological evolution that every day surprises and surpasses us. An introduction or technological evolution that this kind of organizations has already begun to implement is the autonomous vehicles as a mean to an end.

This paper describes and lists the advantages of the introduction of Unmanned Aerial Vehicles in an organization like the navy and also the missions that such robots can perform and optimize.
\end{abstract}

Keywords: UAV, Navy, missions, benefits.

\section{INTRODUCTION}

Over the past few years we have seen, all over the world, technological innovations of great importance. These innovations are present in everyday life societies and in particular within organizations.

The Navy, as multi-purpose organization, must accompany this evolution to benefit of the fulfillment of its objectives. In this continuous development and search innovation, the branch of Aeronautical Science has introduced huge advances. One of the examples is the trends seen with Unmanned Aerial Vehicles (UAV). UAV's are exceptional means to carry out missions that are in responsibility of the Navy.

The introduction of these systems in the Portuguese Navy is one of the primary priorities due to the benefits and via complementarity that these systems bring in the various mission scenarios, noted that in addition to their obvious ability in action radius of expansion of the UAV's navy means allow specially a substantial reduction in operating costs and preservation of human life [1] [2].

The unmanned autonomous vehicle platforms are mostly small or medium sized, so automated that may be semi remotely controlled (by a Ground Control Station) and completely autonomous those being transmitted a more objective task [3] [4]. When this systems are completely autonomous they must incorporate a number of subsystems with a more substantial complexity as regards both the sensors as control systems [2] [4].

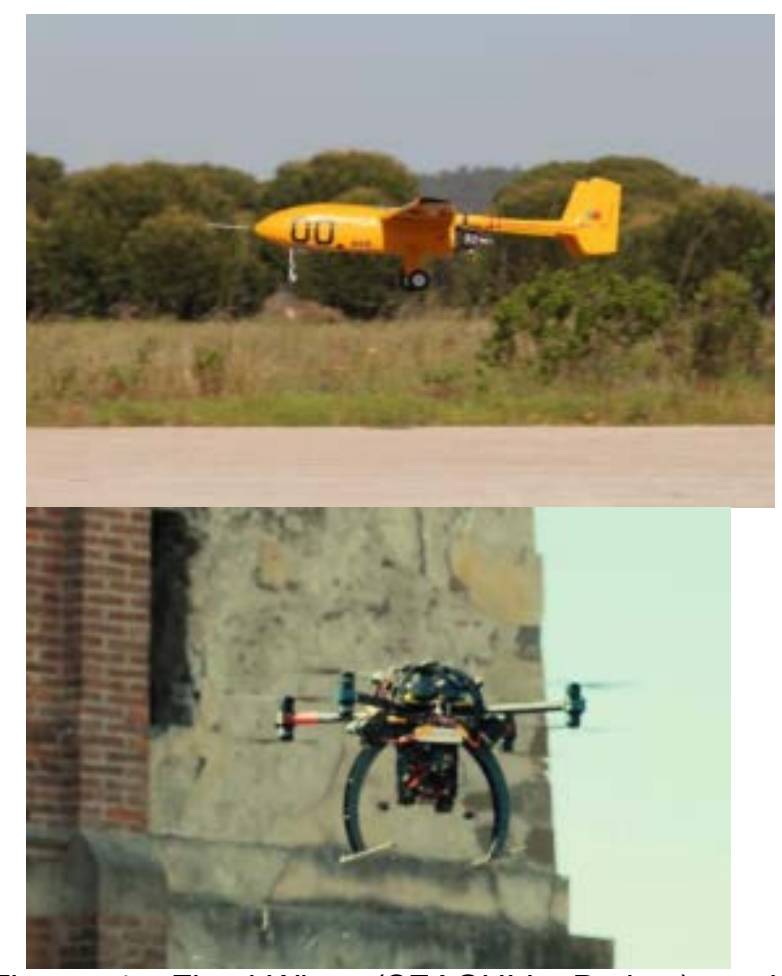

Figure 1: Fixed-Wing (SEAGULL Project) and Multi-rotor (LIFT VI) UAV's

This paper is organized as follows. In Section II are enumerated a major part of the missions/tasks UAV's could perform for organizations, both civil as military. In Section III is presented all the benefits that can be enjoyed by those who use UAV's in the specified missions. They are organized into subsections as: training; cost; material losses; food; 
"Mircea cel Batran" Naval Academy Scientific Bulletin, Volume XIX - 2016 - Issue 1

Published by "Mircea cel Batran" Naval Academy Press, Constanta, Romania // The journal is indexed in: PROQUEST / DOAJ / DRJI / JOURNAL INDEX / I2OR / SCIENCE LIBRARY INDEX / Google Scholar / Crossref /

Academic Keys / ROAD Open Access / OAJI / Academic Resources / Scientific Indexing Services / SCIPIO

rest; temperature. Section IV are presented some conclusions on the matter.

Missions Overview

The missions or tasks that Unmanned Aerial Vehicles could perform should be divided as civil and military tasks/missions.

Some of civil missions/tasks [5]:

- Transport Cargo or Passengers: delivery of cargo or passengers in danger environment conditions;

- Monitoring: crowd, animals, forestry, countryside pollution and air sampling;

- $\quad$ Search and Rescue (SAR): search for and provision of aid to people who are in distress or imminent danger;

- $\quad$ Survey: oil, gas and mineral explorations;

- Scientific Exploration: validity in geological survey and helping the researchers gain a deeper understanding of the environment of Mars, for example;

- Agriculture and Forestry: pesticide spraying services;

- Sports broadcasting and movie making: the audience is filled with wonder at sight of a bird's eye view of splendid stadiums or the special effects in functional movies;

- Engineering and Construction: with the help of high resolution cameras or video recorders it can conduct inspections on power transmission lines between each conducted high-voltage towers [3].
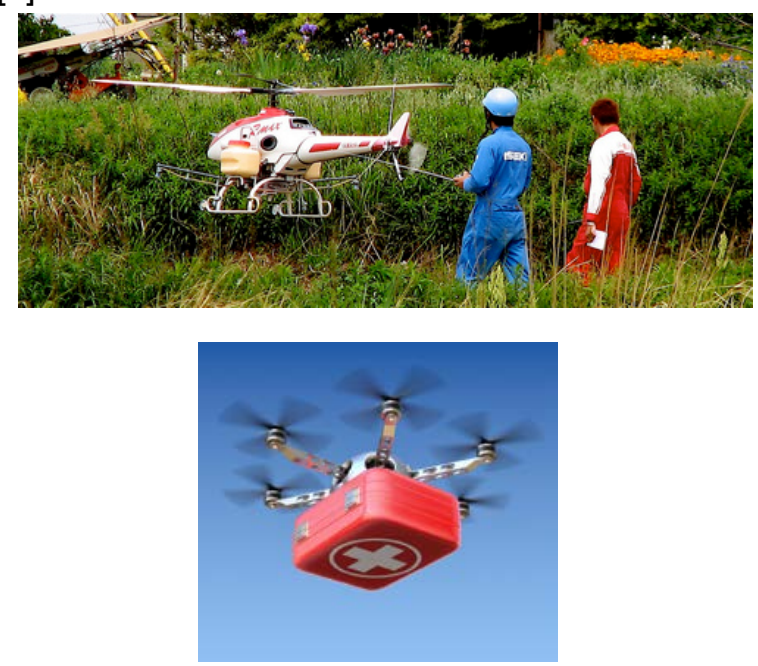

Figure 2 Monitoring fields UAV and First aid UAV
The development of UAV's has been strongly motivated by military applications. After World War II, some nations were looking for aerial vehicles, which have the capability for surveillance, reconnaissance and penetration of hostile terrain without the deployment of human beings in areas of high risk [6].

Some of the military missions/tasks that UAV's can perform:

- Intelligence and Reconnaissance (I\&R): analysis, protection, dissemination inspection and exploration;

- Payload Delivery: special operations forces support and time critical strike;

- Influence Activities (IA): deceive, deter and disrupt enemies;

- Maritime Security: securing allied domestic ports, and protecting ship and maritime infrastructure (piers, docks anchorages and warehouses) against the spectrum of treats from conventional attack to special warfare to specifically targeted terrorist attacks;

- Aerial Warfare: warfare through the air;

- Surveillance: the process of monitoring the behaviour of people, objects or processes for conformity with expected or desired norms;

- Maritime Interdiction Operations (MIO) Support: divert, disrupt, delay, or destroy the enemy's merchant marine trade;

- Border Patrol: monitor, regulate or control the movement of people, animals and goods into as well as out of a country;

- Inspection/identification (ID): this capability will support Homeland Defense (HLD), Antiterrorism/Force Protection (AT/FP), and Explosive Ordnance Disposal (EOD) needs;

- Special Operations Forces (SOF) Support: conducting missions involving unconventional warfare, counter-terrorism, reconnaissance, direct action and military assistance;

- Communication (voice and data): links between units, including connections to a higher command.

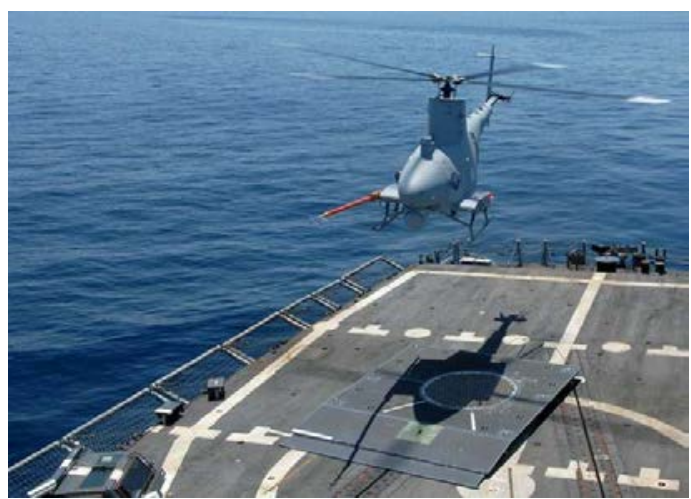


"Mircea cel Batran" Naval Academy Scientific Bulletin, Volume XIX - 2016 - Issue 1 Published by "Mircea cel Batran" Naval Academy Press, Constanta, Romania /I The journal is indexed in: PROQUEST / DOAJ / DRJI / JOURNAL INDEX / I2OR / SCIENCE LIBRARY INDEX / Google Scholar / Crossref / Academic Keys / ROAD Open Access / OAJI / Academic Resources / Scientific Indexing Services / SCIPIO

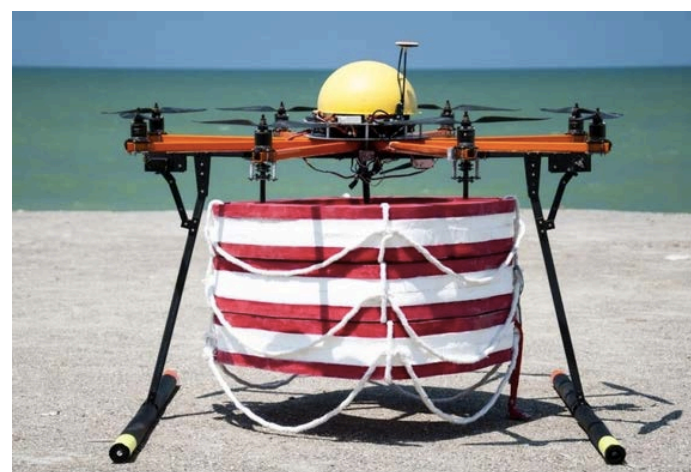

Figure 2: UAV landing on a ship and a UAV with buoys for SAR

It's important to refer that some of this missions that UAV's can perform could be classified both civilian and military missions/tasks.

There are some of these aerial vehicles that were created and designed to perform a single mission or purpose. The majority of them could change his goal task with just an exchange of sensor, communication system alteration or a reprogramming of his software.

\section{MISSIONS BENEFITS}

UAV's, like robots they are, are capable of being adapted to many types of missions depending on the type of sensors or communication that are equipped with. The benefits that these robots bring to human assets organizations like the Navy are a real deal. The benefits are: training; cost; material losses; food; rest; temperature. All these benefits can be categorized at differential gains in comparison to humans performing the same mission or human presence required.

\section{A. Training}

The military personnel who nowadays perform the most dangerous and clandestine missions were, once, ordinary people like the other billions in the world. The way to change that required long years of training, hard training that robots don't require.

UAV's can be constructed in a few short interval of time and a simple introduction of software applications can allow these robots to perform the same mission that a person with long years of training does. No train requires. In a few cases, UAV's are use in an experimental trial and then up to go and ready to the mission.

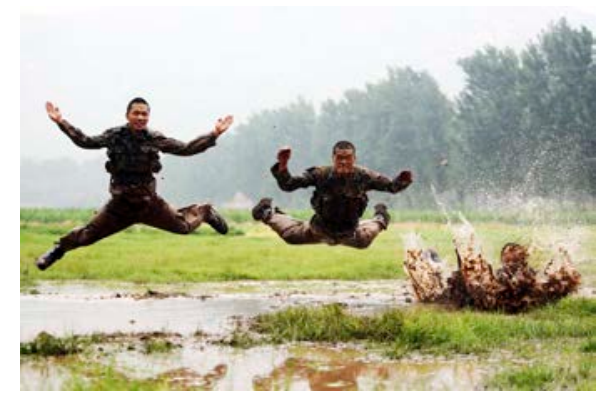

DOI: 10.21279/1454-864X-16-I1-007

(C) 2015. This work is licensed under the Creative Commons Attribution-Noncommercial-Share Alike 4.0 License.

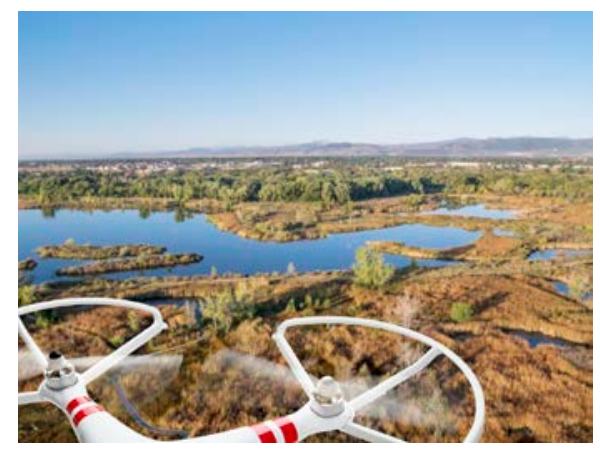

Figure 3: Military training and UAV overflying a swamp

\section{B. Cost}

This matter is one of the most important features. In a dangerous mission where it could be casualties like I\&R missions the value of the losses in case of it happens should be measured before sending someone or something to perform it.

Using as an example a mission of reconnaissance where a team of SEALs were sent to an obscure location and full of enemies. If they are caught, the amount of information that can pass the enemy can be astronomical and may harm other forces as they can still be killed. It has to be considering the money spent in training and logistical essentials all the years of the team that was lost as well the money spent on the other forces that could be harmed.

In the other hand we have a robot that could be substantial less expensive. An UAV with a special camera could perform the same reconnaissance of the team and record it. It would be performed by air and it would be a more useful analyses. A robot flying through the air is much more difficult to capture in one piece to further collection of technological information. Another benefit is that it could be operated by just a single human or even none.

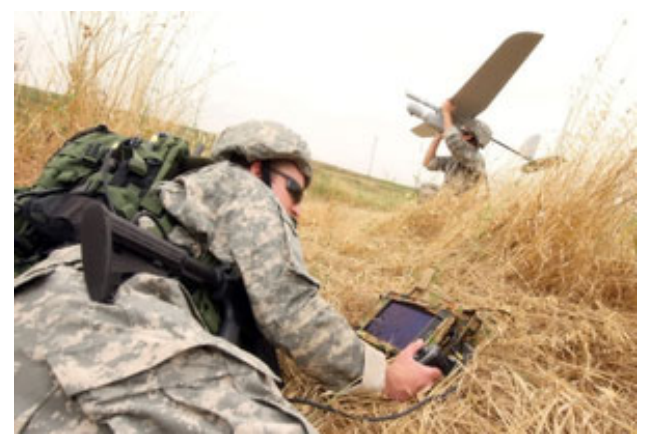

Figure 4: Launch of UAV tele-operated

\section{Material Losses}

Using the same example specified above its relevant the difference of a human casualty or a material lost. Humans have families, feelings and people who depend on their. Robots are just 
"Mircea cel Batran" Naval Academy Scientific Bulletin, Volume XIX - 2016 - Issue 1

Published by "Mircea cel Batran" Naval Academy Press, Constanta, Romania /I The journal is indexed in: PROQUEST / DOAJ / DRJI / JOURNAL INDEX / I2OR / SCIENCE LIBRARY INDEX / Google Scholar / Crossref /

Academic Keys / ROAD Open Access / OAJI / Academic Resources / Scientific Indexing Services / SCIPIO

material created to perform tasks that human used to do, but with benefits.

Here it's being addressed the difference between the existence of human casualties or material losses and both ethical and moral values that these issues raise can't be ignored.

\section{Food}

Eating is a basic need of all human beings. Just like the military that perform the tasks specified above, these also have this necessity, both during the missions and in all the years of training in his military life. All this food, in addition to being cooked or manufactured, has its costs to the respective organizations over the years.

With the introduction of robots to carry out the missions assigned to these soldiers, all of these costs may be spent on batteries or fuel that will be used in the autonomy of these vehicles.

A brief stop to change batteries or supply of fuel will be necessary so that UAVs are able to continue their quests for days and this is a great benefit to be appointed to this issue.

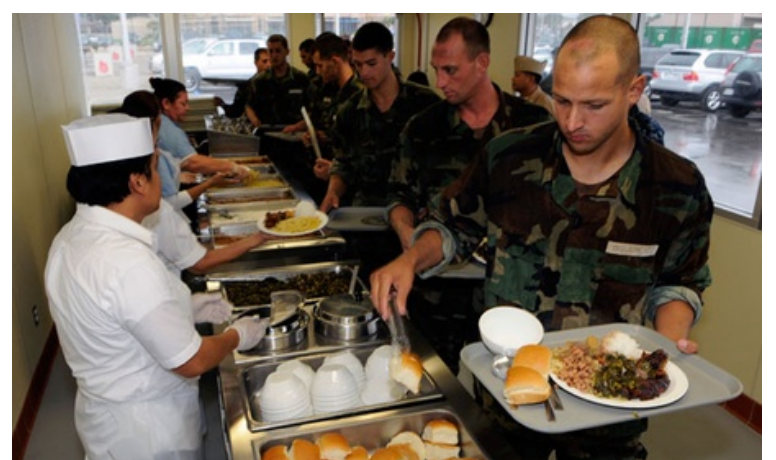

Figure 5: Military having a meal and some of the logistics associated with it

E. Rest

All over the years, the effect of physical and psychobiological tiredness on military had been addressed as one of the major problems on the mental and physical deterioration of retired people from military environments.
No human have infinite resistance. All the missions performed by people couldn't go on and on without any time of rest. The lack of rest results in a decrease of physical and cognitive performance.

With the autonomous vehicles both of these problems are partial solved. The mental deterioration isn't a problem because they are machines. The physical deterioration is remedied with the fabrication of other vehicles. These robots don't need rest. Like robots they are, a single boost of autonomy it's enough to continue their mission for days or weeks, like a change of batteries.

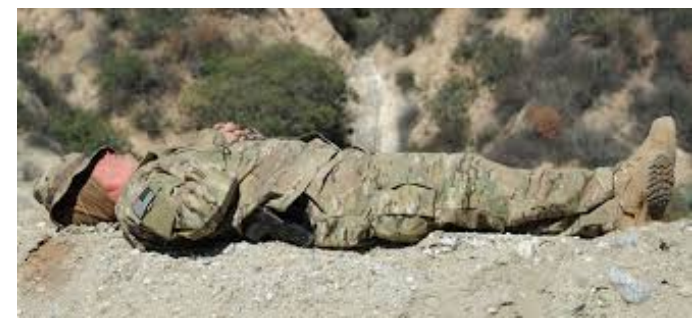

Figure 6: Military resting

\section{F. Temperature}

The temperature and the climate of the places where the missions are performed are one of the biggest concerns of all organizations.

With the change of climate and temperature all the logistics in terms of clothing can change. Extreme temperatures can also be one of the factors for failure in the missions by reducing the performance of operating or impossible accesses.

UAVs are neither cold nor hot. The interval of temperatures that UAVs can support is much wider than human's range.

Climatic characteristics as wind indices can be factors influencing the performance of these robots but they are minimal compared to all the indices that have to be taken into account when a human is in order.

\section{CONCLUSIONS}

In recent years, the research and development of unmanned vehicles have gained much attention in the academic and military communities worldwide. Objects like unmanned aircraft and intelligent robotics are widely investigated as they have potential applications in the military and civil domains. They are developed to be capable of working autonomously without a human pilot.

The main goal of this work was the demonstration of why the Unmanned Aerial Vehicles are an important introduction in organizations, namely the Navy. Taking into account the wide range of multi-purpose missions that UAV's could perform instead of humans, it's important to know its benefits in terms of logistic and money spent.

In this paper is statement the various missions that UAV's do and appointed its benefits in terms of training, cost, material losses, food, rest and temperature.

In a command and management decision every aspects should be taking into account so that the decision could be the most rightful to everyone and this paper could be presented as one more help in this way. 
"Mircea cel Batran" Naval Academy Scientific Bulletin, Volume XIX - 2016 - Issue 1

Published by "Mircea cel Batran" Naval Academy Press, Constanta, Romania // The journal is indexed in:

PROQUEST / DOAJ / DRJI / JOURNAL INDEX / I2OR / SCIENCE LIBRARY INDEX / Google Scholar / Crossref /

Academic Keys / ROAD Open Access / OAJI / Academic Resources / Scientific Indexing Services / SCIPIO

\section{BIBLIOGRAPHY}

[1] Manley J. (2008), Unmanned Surface Vehicles, 15 years of development, In Proc. of MTS/IEEE Oceans'08

[2] Fletcher B. (2000), UUV Master Plan: A Vision for Navy UUV Development, Proceedings of the Oceans Conference

[3] Cai G. et all (2010), An overview on development of miniature unmanned rotorcraft systems. Frontiers of Electrical and Electronic Engineering in China

[4] Watts A., Ambrosia V. and Hinkley E. (2012), Unmanned aircraft systems in remote sensing and scientific research: Classification and considerations of use, Remote Sensing

[5] Nehme C. (2006), UAV Mission Hierarchy Boston: Humans and Automation Laboratory, Massachusetts Institute of Technology

[6] Heisenbeiss H. (2004), A mini unmanned aerial vehicle (UAV): system overview and image acquisition, International Archives of Photogrammetry, Remote Sensing and Spatial Information Sciences 